\section{International Scientific Journal Theoretical \& Applied Science}

\author{
p-ISSN: 2308-4944 (print) e-ISSN: 2409-0085 (online) \\ Year: $2016 \quad$ Issue: 6 Volume: 38 \\ Published: $30.06 .2016 \quad$ http://T-Science.org
}

Sergey Alexandrovich Mishchik Associate Professor, Candidate of Pedagogical Science, Corresponding member of International Academy TAS, Assistant professor Department of Physics, State Maritime University Admiral Ushakov, Russia sergei_mishik@mail.ru

SECTION 21. Pedagogy. Psychology. Innovation in Education.

\title{
MAIN AREAS PEDAGOGOMETRIC MATHEMATICAL MODELING EDUCATIONAL PROCESS
}

\begin{abstract}
The main directions of mathematical modeling pedagogometric the educational process on the basis of a synergistic approach to the process of identity formation, set the basic heuristic potential synergistic approach to the analysis of education-enforcement process in terms of information and communication online media, as well as the use of the twelve pointed star Ertsgammy as a leading formative processes relative-enforcement hyperspace of life, as well as psychological and pedagogical activity theory, psycho-pedagogical system analysis and the theory of the formation of mental actions.
\end{abstract}

Key words: pedagogometric mathematical modeling, pedagogometric, consistency, integrity, the subject of activity, personality analysis, star Ertsgammy, educational space.

Language: Russian

Citation: Mishchik SA (2016) MAIN AREAS PEDAGOGOMETRIC MATHEMATICAL MODELING EDUCATIONAL PROCESS. ISJ Theoretical \& Applied Science, 06 (38): 137-141.

Soi: http://s-o-i.org/1.1/TAS-06-38-29 Doi: crossef http://dx.doi.org/10.15863/TAS.2016.06.38.29

\section{УДК 372.851}

\section{ОСНОВНЫЕ НАПРАВЛЕНИЯ ПЕДАГОГОМЕТРИЧЕСКОГО МАТЕМАТИЧЕСКОГО МОДЕЛИРОВАНИЯ ОБРАЗОВАТЕЛЬНОГО ПРОЦЕССА}

Аннотация: Рассмотрены основные направления педагогометрического математического моделирования образовательного процесса на основе синергетического подхода к процессу формирования личности, устанавливаются базисные эвристические возможности синергетического подхода к анализу образовательного прочесса в условиях информачионно-коммуникативной интернет-среды, а также применение двенадияати конечной звезды Эригаммы в качестве ведущего формообразовательного процесса относительно гиперпространства жизнедеятельности, а также психолого-педагогической теории деятельности, психолого-педагогического системного анализа и теории формирования умственных действий.

Ключевые слова: педагогометрическое математическое моделирование, педагогометрика, системность, целостность, субъект деятельность, личность, анализ, звезда Эригаммы, образовательное пространство.

Педагогометрическое моделирование учебного общее направление математическое процесса отражает автоматизации образовательных технологий, направленных на совершенствование базисной, фундаментальной и широкопрофильной подготовки специалистов, которые должны ориентироваться в общей структуре производства, совокупности методов его самоорганизации и этапах формирования профессионального мастерства.
Педагогометрическое

математическое моделирование учебного процесса связывается с современным этапом развития науки в целом, характеризующимся интеграционными процессами и сопровождающимся парадигмальными сдвигами, что связывается с функцией освоения синергетического подхода в отечественном обществознании в форме становления теории самоорганизации [1] .

K настоящему времени сложилось широкое междисциплинарное направление, объединяющее 
представителей естественно-научного и социально-гуманитарного знания, связанного с развитием синергетики и многомерности еe приложения. Возникающий синергеанализ социальных процессов, с трансформаций в системе образования и социальном управлении, коэволирует человека и природу. Основные положения синергетики, как теории развития сложных систем в их целостном представлении, устанавливают базисные эвристические возможности синергетического подхода к анализу образовательного процесса в условиях информационно-коммуникативной интернетсреды.

В современных условиях социология накопила значительный объём знаний по проблемам моделирования социальной динамики, ведутся разработки по общей методологии построения социолого-математических моделей, как инструмента исследования социальных и образовательных процессов. В социологоматематических моделях раскрывается сложность, многомерность, многоуровневостъ, многокомпонентность, открытость, целостность и динамичность образовательного процесса через синергетический анализ развития учебной деятельности [15].

В этом случае математическое моделирование, как создание модели - образа оригинала, выражается в изучении образовательного процесса с помощью реализуемых на компьютерах вычислительнологических алгоритмов. При этом важно учесть, что адекватность моделирования социальных процессов обязана математически отображать материальную и духовную составляющую. Это выразилось в идеи двойственности и симметрии с учётом альтернативности, необратимости, неустойчивости и рефлективности, как особенности социальных процессов. На языке высоко абстрактной математики это представляется понятиями — категорий и фунторов.

Образовательный процесс, развитие устойчивой пары «учитель-ученик», рассматривается на основе идеи двойственности и симметрии. В разрабатываемых моделях системы общественного воспроизводства выделяются десять уравнений для определения показателей центрической модели. Для моделирования образовательного процесса, как самореферирующей системы при моделировании сознания и рефлектирующих функций, требуется отображение удвоенного признакового пространства - надстройки. Необходимость учёта рефлективности и историчности образовательного процесса связывается с развитием моделирования основанного на цепях Маркова.
В математическом моделировании образовательного процесса указывается на необходиость: проводить учёт параметров информационно-когнитивной составляющей, как элементов морфогенетических, так и трансмутационных изменений, направленных на введения социальных переменных в модель системы общественного воспроизводства; учёта учебных навыков в качестве независимого третьего аргумента образовательной функции, такой же кумуляты, как знания и умения.

Поэтому существуют базовые математические модели образовательного процесса относительно информационноэнтропийного подхода к отображению нелинейности - для морфогенетических моделей, а также сложности - для репродуктивных моделей — на разных этапах моделирования.

Педагогометрическое математическое моделирование учебного процесса связывается с совершенствованием качества образования. При этом в основе проектирования образовательного процесса используют алгоритм информационноматематического моделирования, когда математическое моделирование проводится в соответствии с технологической моделью уровня личностных достижений обучаемого. Для эффективного управления и математического моделирования обучения применяют комплексы прикладной математики и кибернетики [2] .

Одним из направлений математического моделирования организации учебного процесса является использование методов теории графов и линейной алгебры. Для установления факторов, влияющих на систему организации учебного процесса, применяется метод экспертных оценок. При разработке методики контроля за качеством обучения используются методы математической статистики. В решении задач оптимизации учебного процесса применяют методы линейного программирования.

В целом, при математическом моделировании, учебный процесс представляется в виде структурного графа, позволяющего анализировать взаимосвязи между различными параметрами влияющими на обучение студентов. На основе структурного графа анализируется математическая модель организации учебного процесса в виде системы линейных алгебраических уравнений, где в качестве коэффициентов выделяются весовые показатели параметров учебного процесса. С помощью методов математической статистики устанавливаются среднестатистические показатели, влияющие на качество обучения [16]

Дальнейшее математическое моделирование учебного процесса связывается с разработкой 
авторских инструментальных сред, позволяющих моделировать процессы интерактивного обучения, создавать образовательные информационные ресурсы в автоматизированном режиме, в том числе их мета-описания в соответствии с международными стандартами. Это позволяет применять методы прикладного системного анализа, CASE-технологий; методы построения формальных моделей бизнес-систем, математического аппарата раскрашенных сетей Петри, цепей Маркова; методологии педагогического проектирования.

В целом, это позволяет рассматривать информационную модель жизненного цикла образовательного информационного ресурса с учетом этапа педагогического математического проектирования. При этом разрабатывается и исследуется модель динамики процессов жизненного цикла образовательного информационного ресурса на основе формализмов сетей Петри и цепей Маркова [3] .

На основе теории цепей Маркова разрабатывается стохастическая модель управления этапами жизненного цикла образовательного информационного ресурса, учитывающая время создания и общую стоимость информационного ресурса. Новый подход к моделированию и проектированию образовательного информационного ресурса, отличается от общепринятого тем, что в стандартную методологию проектирования образовательного информационного ресурса, как информационной системы, включены функции математического педагогического проектирования.

Дальнейший анализ результатов математического проектирования образовательного процесса связывается с более широким использованием методов математической статистики для обработки информации, получаемой в результате проведения педагогических образовательных процессов, которые учитывают вероятностный характер педагогических явлений, а также многофакторность педагогической среды и вводят в практику математического моделирования методы выборочных обследований [4].

Выделенные педагогометрического направления моделирования образовательного процесса отражают проблемы развития педагогометрического анализа.

Эффективность медатетической модели целостно-системного цикла учебной деятельности определяется дальнейшим развитием психологической теории деятельности, психолого-педагогического системного анализа и теории формирования интеллекта $[5,6]$.

Синергетическое развитие выделенных проблем связывается с построением физикоматематического образа базисных образовательных задач задач. Можно рассматривать любые формы представления данных процессов: от механических до оболочных технологий, однако механическая модель позволит лучше представить установленные закономерности $[12,13,14]$.

Количественный анализ числа структурных элементов гиперпространства целостносистемных циклов жизнедеятельности, структурных элементов циклических процессов жизнедеятельности, психолого-педагогического системного анализа, теории формирования интеллекта указывает на конкретную определённость этой меры - двенадцать (12) элементов. В целостно-системном цикле жизнедеятельности выделяются следующие целостно-системные элементы: от начального субъекта до супер-субъекта, который открывает последующий цикл развития субъекта жизнедеятельности [7,8].

Элементарное гиперпространство целостносистемных циклов жизнедеятельности представляется двенадцатилучевой звездой Эрцгаммы, элементами которой являются: ориентировочная жизнедеятельность, исполнительная жизнедеятельность, контрольная жизнедеятельность, ориентировочная деятельность, исполнительная деятельность, контрольная деятельность, ориентировочное действие, исполнительное действие, контрольное действие, ориентировочная операция, исполнительная операция, контрольная операция.

Количественное представление психологопедагогического системного анализа также актуализирует двенадцать (12) системных действий: от выделения объект изучения как систему до представления прогноза развития объекта. Выделенная совокупность системных действий составляет определённую «Азбуку Жизни» [9].

Анализ базисных основ теории формирования интеллекта в условиях целостносистемной жизнедеятельности устанавливает двенадцать (12) этапов формирования интеллекта: от целостно-системная ориентационности до це-лостно-системная духовности [10].

Совместное сочетание теории гиперпространства целостно-системных циклов жизнедеятельности, психологической теории деятельности, психолого-педагогического системного анализа и теории формирования интеллекта в различных соотношениях создают разнообразные формы и структуры 
жизнедеятельности, соответствующие им системы воспитания и образования, а также результаты данных процессов: от индивидуума до личности; от «частичного» специалиста до широкопрофильного. Ведущим глаголом учебнопрофессиональной деятельности можно считать крутить (ученика) в зависимости от условий образовательного пространства [11].

\section{References:}

1. Astafieva ON (2002) Heuristic possibilities of synergy in the study of modern-sotsi okulturnyh process: dis. ... Doctrinal. Philosophy. Sciences: 24.00.01 / O.N.Astafeva - Moscow, 2002. - 371 p.

2. Chuiko LV (2006) Mathematical methods in pedagogic - the boom as a condition for improving the quality of education: Dis. ... Cand. ped. Sciences: 13.00.01 / LV Chuyko. Tiraspol, 2006. $-182 \mathrm{p}$.

3. Gritsenko EM (2004) Process Managementzhiz-cycle educational information-resources: dis. ... Cand. those. Sciences: 05.13.01 / EM Gritsenko. - Krasnoyarsk, 2004. - 177 p.

4. Gurtovaya NG (2004) Role and place of mathematical methods cal statistics in pedagogical researchtions: dis. ... Cand. ped. Sciences: 13.00.02 / GN Gurtovaya. - Nizhny Novgorod, 2004. - 200 p.

5. Mishchik SA (2014) Pedagogometrika and mathematical modeling educational activity. Materialy Mezhdunarodnoy nauchnoy konferenctsii "Modern mathematics in science" - 30.06.2014. ISJ Theoretical \&Applied Science 6(14): 54-56 Caracas, Venezuela. doi: http://dx.doi.org/10.15863/TAS.2014.06.14.10

6. Mishchik SA (2014) Simulation training activity methods of mathematical logic. Materialy Mezhdunarodnoy nauchnoy konferenctsii "Eurapean Science and Education" - 30.07.2014. ISJ Theoretical \&Applied Science 7(15): 72-74 Marseille, France. doi: http://dx.doi.org/10.15863/TAS.2014.07.15.13

7. Mishchik SA (2014) Mathematical modeling system integrity-cycle of life activity - first goal pedagogometriki. Materialy Mezhdunarodnoy nauchnoy konferenctsii "European Applied Sciences" - 30.08.2014. ISJ Theoretical \&Applied Science 8(16): 77-79. Aix-en-Provence, France. doi: http://dx.doi.org/10.15863/TAS.2014.08.16.13

8. Mishchik SA (2014) Mathematical modeling system integrity-curricular activities - the second problem pedagogometriki. Materialy
Mezhdunarodnoy nauchnoy konferenctsii "European Innovation" - 30.09.2014. ISJ Theoretical \&Applied Science 9(17): 126-128 Martigues, France. doi: http://dx.doi.org/10.15863/TAS.2014.09.17.21

9. Mishchik SA (2014) Mathematical modeling holistic-systemic communicative activity - the third task pedagogometriki. Materialy Mezhdunarodnoy nauchnoy konferenctsii "European Scientific Achievements" 30.10.2014. ISJ Theoretical \&Applied Science 10(18): 45-47 Brighton, UK. doi: http://dx.doi.org/10.15863/TAS.2014.10.18.11

10. Mishchik SA (2014) Mathematical modeling integrity - system performance subject - fourth task pedagogometriki. Materialy Mezhdunarodnoy nauchnoy konferenctsii "Eurapean Science and Technology" 30.11.2014. ISJ Theoretical \&Applied Science 11(19): 51-54 Southampton, UK. doi: http://dx.doi.org/10.15863/TAS.2014.11.19.10

11. Mishchik SA (2015) Pedagogometrik - science and academic subject. Materialy Mezhdunarodnoy nauchnoy konferenctsii "European Technology in Science" 28.02.2015. ISJ Theoretical \& Applied Science 02 (22): 103-106 Malmö, Sweden. doi: http://dx.doi.org/10.15863/TAS.2015.02.22.17

12. Tokmazov GV (2014) Matematicheskoe modelirovanie $\mathrm{v}$ uchebno-professional'noy deyatel'nosti. Materialy Mezhdunarodnoy nauchnoy konferentsii «Modern mathematics in science» - 30.06.2014. ISJ Theoretical \& Applied Science 6(14): 44-46. - Caracas, Venezuela. http://dx.doi.org/10.15863/TAS.2014.06.14.8

13. Tokmazov GV (2014) Analysis says study skills in the study of mathematics, Materialy Mezhdunarodnoy nauchnoy konferenctsii "Eurapean Science and Education" 30.07.2014. ISJ Theoretical \&Applied Science 6(14): 72-74 Marseille, France. doi: http://dx.doi.org/10.15863/TAS.2014.06.14

14. Tokmazov GV (2014) Mathematical modeling research skills in educational activity methods 


\begin{tabular}{l|lrl|l|ll} 
& ISRA (India) & $=\mathbf{1 . 3 4 4}$ & SIS (USA) & $=\mathbf{0 . 9 1 2}$ & ICV (Poland) & $=\mathbf{6 . 6 3 0}$ \\
Impact Factor: & ISI (Dubai, UAE) $=\mathbf{0 . 8 2 9}$ & PUHL (Russia) $=\mathbf{0 . 2 3 4}$ & PIF (India) & $=\mathbf{1 . 9 4 0}$ \\
& GIF (Australia) & $\mathbf{0 . 5 6 4}$ & ESJI (KZ) & $=\mathbf{1 . 0 4 2}$ & IBI (India) & $\mathbf{= 4 . 2 6 0}$ \\
& JIF & $\mathbf{1 . 5 0 0}$ & SJIF (Morocco) & $=\mathbf{2 . 0 3 1}$ & & \\
\hline
\end{tabular}

of probability theory. Materialy Mezhdunarodnoy nauchnoy konferenctsii "European Science and Technology" 30.11.2014. ISJ Theoretical \&Applied Science 11(19): 66-69 Southampton, United Kingdom. doi:

http://dx.doi.org/10.15863/TAS.2014.11.19.13

15. Shvedovskii VA (2010) sociological and mathematical models in the study of social processes: dis. ... Doctrinal. soc. Sciences: 22.00.01 / VA Shvedov-sky. - Moscow, 2010. $319 \mathrm{p}$.

16. Sygotina MV (2003) Modeling of the Organization of the educational process in a technical university: dis. ... Cand. those. Sciences: 05.13.01 / MV Sygotina. - Bratsk, 2003. -140 p. 